\title{
Ambivalence and evaluative response amplification
}

\author{
CHARLES S. CARVER \\ University of Miami, Coral Gables, Florida 33124
}

FREDERICK X. GIBBONS

University of Kansas, Lawrence, Kansas 66044

WALTER G. STEPHAN

New Mexico State University, Las Cruces, New Mexico 88003

and

DAVID C. GLASS and IRWIN KATZ

Graduate Center, City University of New York, New York, New York 10021

\begin{abstract}
Each subject evaluated an interviewee on the basis of information in a transcript. The interviewee was portrayed either favorably or unfavorably; he was labeled as "handicapped" or "Chicano," or he was not labeled. Half the subjects were exposed to a pretreatment designed to induce ambivalent affect toward the physically handicapped. These subjects subsequently evaluated the favorably portrayed handicapped interviewee more positively, and the unfavorably portrayed handicapped interviewee more negatively, than did control subjects. Moreover, this effect generalized to Chicano and nonstigmatized stimulus persons. Independent of this finding, subjects' evaluations of the handicapped were more favorable than evaluations of the other stimulus persons.
\end{abstract}

It has been suggested that ambivalence creates a tendency toward behavioral instability, in which positive or negative responses toward the object of the ambivalence are amplified, or exaggerated (e.g., Fenichel, 1945). Whether any specific response is positive or negative presumably depends upon the behavioral context; that is, if the person is momentarily construed in a favorable light, the response will be positive; if he is seen in an unfavorable light, the response will be negative. Once the direction of the response has been determined, however, its intensity will be greater if there was initial ambivalence than if there was not.

Although this hypothesis originally centered on the ambivalence felt toward specific individuals, the basic idea seems applicable to feelings toward groups. If a person has ambivalent attitudes toward a given social category, such as a minority group, it may be that he will display amplified responses toward any member of that group. This argument may be relevant to outgroups

As their contributions to the paper were roughly equivalent, the first three authors are listed alphabetically. The research reported in this paper was supported by grants to David C. Glass and Irwin Katz from the National Science Foundation (GS-37976X and GS-37977X), and by a grant to Walter G. Stephan from the National Institute of Mental Health (MH-22249). Requests for reprints should be sent to Walter G. Stephan, Department of Psychology, New Mexico State University, Las Cruces, New Mexico 88003. seen as disadvantaged and perhaps victimized by social injustice or impersonal fate, but also regarded as inferior and potentially threatening. Dienstbier (1970, Study 1$)$, for example, has provided data consistent with this reasoning.

Other recent studies of impression formation, however, have yielded results that conflict sharply with Dienstbier's (1970) findings. Subjects have been found to evaluate blacks more favorably than whites (Carver, Glass, Snyder, \& Katz, 1977), most reliably when the stimulus persons had been negatively portrayed. The same pattern of evaluations also has been demonstrated toward stimulus persons identified as physically handicapped (Scheier, Carver, Schulz, Wishnick, Glass, \& Katz, in press). These findings raise serious questions about the amplification hypothesis, at least as it applies to impression formation.

One possible interpretation for the Carver et al. (1977) and Scheier et al. (in press) findings is that their subjects' ambivalence may not have been fully aroused. As subjects in those experiments had no actual contact with the interviewees, the only cue to evoke ambivalence was a label indicating that the interviewee was black or handicapped. If this cue did not arouse ambivalent affect, there would be no reason to expect amplification to occur. This line of reasoning is consistent with the fact that most other support for the ambivalenceamplification hypothesis has occurred where subjects 
interacted verbally and physically with the stimulus person (e.g., Gergen \& Jones, 1963; Katz, Cohen, \& Glass, 1975).

Nevertheless, it seems reasonable that if ambivalence could be fully aroused in subjects, amplification could be obtained even in impression formation. Indeed, such a study would seem to provide an ideal opportunity to test experimentally the hypothesis that ambivalence leads to both positive and negative response amplification. The present study was designed to provide such a test.

A separate issue addressed in the present study is whether the amplified responses would generalize beyond the initial object of the ambivalence. One possibility is that the occurrence of extreme responses requires the stimulus person to be a member of the group toward which ambivalence has been aroused; thus there would be no generalization at all. A second possibility is that amplification is a joint function of aroused ambivalence and outgroup membership, but not necessarily the same outgroup as evoked the ambivalent affect. Thus amplification might generalize, but only to another outgroup member. The third possibility is that ambivalence, once aroused, will produce extreme responses toward any stimulus person encountered while one is experiencing the feelings of ambivalence. These alternatives were assessed in the present study.

\section{METHOD}

Subjects, tested individually, were 248 female undergraduates at the University of Texas; 18 others were eliminated from the data analysis, 11 because postexperimental questions revealed that they had not read the pretreatment material (see below), and 7 because they indicated having suspicions about that material or about the confederate who presented it. Subjects were randomly assigned to one of three stimulus group conditions and to one of two favorability conditions (described more fully below). Prior to the laboratory procedure, half of each group was exposed to the major experimental manipulation, an ambivalence-inducing pretreatment.

\section{Pretreatment}

A male confederate approached the subject while she waited in the hall for the experiment to begin (all subjects waited equal time, whether receiving the pretreatment or not). The confederate told the subject that he was circulating a petition intended for the student-faculty senate (of which he was a member), urging a campus-wide referendum concerning enrollment of handicapped students at the university. A cover page summarized two proposals ostensibly advanced by opposing factions in the senate. One urged the easing of admissions criteria for physically handicapped students; the other called for raising those standards to the level currently maintained for nonhandicapped students (thus reducing handicapped enrollment by $20 \%-25 \%$ ). The paragraph in support of increased admissions for the handicapped admonished the student populace for avoiding "uncomfortable" questions involving the rights of handicapped persons. It pointed out that those persons continually face barriers to equal educational and economic opportunities. This paragraph was intended to evoke feelings of sympathy toward the handicapped. The next paragraph presented an opposing argument, citing the likelihood that a sudden increase in the enrollment of handicapped students would cause admission to be denied to more qualified students, and the fact that funds would have to be diverted from other important projects to build additional special facilities for handicapped students. This paragraph was intended to evoke negative affect toward the handicapped.

All arguments were worded in such a way that they seemed reasonable. It was stressed that support existed for each position in the senate, and that students should be fully informed of the issues involved.

\section{Transcript Conditions}

The experimenter then approached the subject and escorted her to an experimental cubicle. The procedures that followed duplicated those used by Carver et al. (1977). The subject was told that, as part of a control group for an impression-formation study, her task was to rate an interviewee on the basis of a typed transcript. There were three stimulus-group conditions: handicapped, Chicano, and nonstigmatized. In the nonstigmatized condition, a line across the top of each transcript page read "Dan B., Male, 19, 5'9", 150 pounds." In the handicapped condition, "Handicapped" was added at the end. The following additional question also was inserted into the interview transcripts in this condition: "How long have you been in that wheelchair?" The interviewee's reply was "All my life, as long as I can remember. As a paraplegic, I just can't get around without it." The Chicano transcript was modeled after the handicapped version. "Chicano" was substituted for "Handicapped" at the top of the pages, and the question, "Were you born in Mexico or the U.S.?" and the response, "In San Antonio, I've lived there all my life," were substituted for the question and answer about the wheel chair. All transcripts were otherwise identical within each of the two favorability conditions. In the favorable transcript, the interviewee was portrayed as a college student with an upper middle-class background, high ambitions, varied interests, and many friends. In the unfavorable transcripts, the interviewee was portrayed as a college student from a lower class background, with few friends, no particular interests, and no plans for the future. The design thus was a 2 (pretreatment vs. no pretreatment) by 2 (favorable vs. unfavorable portrayal) by 3 (handicapped, Chicano, nonstigmatized) factorial.

After reading the transcript, each subject made ratings of the interviewee on a series of 11-point scales anchored by polaropposite adjectives (e.g., "intelligent" vs. "unintelligent," "hardworking" vs. "lazy"). The ratings were summed to yield an overall evaluation (high scores indicating favorable evaluations).

\section{RESULTS}

Analysis revealed that the favorably portrayed interviewees were rated more positively than the unfavorably portrayed interviewees $(\mathrm{p}<.0001)$. More importantly, there also was a highly significant Favorability by Pretreatment interaction $[\mathrm{F}(1,236)=17.77, \mathrm{p}<.0001]$, such that the favorably portrayed interviewees were rated more negatively following pretreatment than with no pretreatment $[\mathrm{t}(236)=3.84, \mathrm{p}<.0003]$, and the unfavorably portrayed interviewees were rated more negatively following pretreatment than with no pretreatment $[\mathrm{t}(236)=2.08, \mathrm{p}<.04]$ (see Table 1$)$.

To determine the generality of the amplification effect, the strength of the Favorability by Pretreatment interaction was computed separately for each stimulus group, using the overall error term (cf. Winer, 1971). 
Table 1

Mean Evaluations of the Interviewees

\begin{tabular}{|c|c|c|c|c|c|c|c|c|}
\hline & \multicolumn{4}{|c|}{ Favorable Portrayal } & \multicolumn{4}{|c|}{ Unfavorable Portrayal } \\
\hline & \multicolumn{2}{|c|}{$\begin{array}{c}\text { Pretreat- } \\
\text { ment }\end{array}$} & \multicolumn{2}{|c|}{$\begin{array}{c}\text { No Pretreat- } \\
\text { ment } \\
\end{array}$} & \multicolumn{2}{|c|}{$\begin{array}{c}\text { Pretreat- } \\
\text { ment }\end{array}$} & \multicolumn{2}{|c|}{$\begin{array}{c}\text { No Pretreat- } \\
\text { ment }\end{array}$} \\
\hline & Mean & $\mathrm{n}$ & Mean & $\mathbf{n}$ & Iean & $\mathrm{n}$ & Mean & $\underline{\mathrm{n}}$ \\
\hline $\begin{array}{l}\mathrm{H} \\
\mathrm{C} \\
\mathrm{N}\end{array}$ & $\begin{array}{l}104.47 \\
101.33 \\
101.61\end{array}$ & $\begin{array}{l}19 \\
18 \\
18\end{array}$ & $\begin{array}{l}88.10 \\
93.95\end{array}$ & $\begin{array}{l}21 \\
21 \\
20\end{array}$ & $\begin{array}{l}59.95 \\
57.00\end{array}$ & $\begin{array}{l}20 \\
20 \\
21\end{array}$ & $\begin{array}{l}71.39 \\
64.29 \\
58.96\end{array}$ & $\begin{array}{l}23 \\
24 \\
23\end{array}$ \\
\hline
\end{tabular}

Note-Higher numbers indicate more favorable evaluations. $H=$ handicapped; $C=$ Chicano; $N=$ nonstigmatized.

The interaction proved to be significant for interviewees labeled as handicapped $(p<.04)$ and for those labeled as Chicano $(\mathrm{p}<.01)$, and marginally significant for those who were unlabeled $(\mathrm{p}<.08)$. This wide generality was also reflected in the virtually total absence of a second-order interaction.

The overall analysis also revealed a significant main effect for stimulus group $[\mathrm{F}(2,236)=8.98, \mathrm{p}<.0003]$, reflecting the fact that handicapped interviewees were rated more positively overall than either Chicanos or the nonstigmatized (ps <.01). Ratings of the latter two groups did not differ reliably from each other. These findings replicated the Scheier et al. (in press) "sympathy" effect with respect to the handicapped interviewees, and the Carver et al. (1977) finding that the sympathy effect does not extend to Chicanos.

\section{DISCUSSION}

When subjects were induced by a pretreatment to focus their attention on both positive and negative feelings toward the handicapped, response amplification occurred, supporting the ambivalence-amplification hypothesis. The pattern of results also indicated that the effect was not specific to the group toward whom ambivalence had been generated. As in earlier studies, amplified responses did not occur without experimental heightening of ambivalence.

Subjects also displayed a sympathy reaction to the handicapped but not to Chicanos, replicating earlier findings. The possibility that the sympathy effect represents an attempt by subjects to behave in a socially desirable way (cf. Crowne \& Marlowe, 1964) is rendered somewhat untenable by the recent finding (Carver, Glass, \& Katz, 1978) that ratings of the handicapped stay high even under the conditions of a "bogus pipeline" paradigm. Perhaps the sympathy findings represent an instance of Kelley's (1971) augmentation principle of attribution: that observers credit actors for struggling against an environment that inhibits success. Subjects may have inferred such a struggle for handicapped interviewees and rewarded them with more positive evaluations. Constraints against Chicanos' success may have been less apparent, thus minimizing augmentation for them.

One final point should be made regarding the response amplification effect demonstrated here. Katz and his associates have favored a cognitive interpretation of the amplification process, regarding the extreme responses as "convenient, lowcost modes of resolving attitudinal conflict" (Katz et al., 1975, p. 435). They suggest that the inconsistency between conflicting attitudes is minimized by cognitively and behaviorally emphasizing one of the feelings and deemphasizing the other. This principle seems inadequate by itself, however, to account for the generalization of amplification in the present study. That is, it seems unlikely that an inconsistency between positive and negative attitudes toward the handicapped could be resolved by exaggerating a response toward a person who was not handicapped. A more reasonable interpretation of the generalization effect may be that the conflict between ambivalent attitudes produces a state of arousal. This arousal, then, may be responsible for the generality of the response amplification. That is, once favorability cues have determined the direction of the response, the arousal may cause the response to be more extreme.

This interpretation would be consistent with either of two theoretical analyses: drive theory and attribution theory. Arousal may have caused the prepotent response to be expressed more fully, thus causing ratings in the pretreatment condition to be more extreme than in the no-pretreatment condition. Alternatively, it may be that arousal became psychologically dissociated from its initial source due to the change in context (cf. Zillman, Johnson, \& Day, 1974). That is, as the subject read the interview transcript, she may have attributed her arousal to an evaluative reaction to the interviewee. The present study does not allow us to distinguish between these two possibilities. Both alternatives, however, suggest that the extreme responses produced by ambivalence are merely a subset of a larger class of responses caused by the presence of arousal.

\section{REFERENCES}

Carver, C. S., Glass, D. C., \& Katz, I. Favorable evaluations of blacks and the handicapped: Positive prejudice, unconscious denial, or social desirability? Journal of Applied Social Psychology, 1978, 8, 97-106.

Carver, C. S., Glass, D. C., SNyder, M. L., \& Katz, I. Favorable evaluations of stigmatized others. Personality and Social Psychology Bulletin, 1977, 3, 232-235.

Crowne, D. P., \& Marlowe, D. The approval motive: Studies in evaluative dependence. New York: Wiley, 1964.

Dienstbier, R. A. Positive and negative prejudice: Interaction of prejudice with race and social desirability. Journal of Personality, 1970, 38, 198-215.

FENICHEL, O. The psychoanalytic theory of neurosis. New York: W. W. Norton, 1945.

GERGEN, K. J., \& Jones, E. E. Mental illness, predictability, and affective consequences as stimulus factors in person perception. Journal of Abnormal and Social Psychology, 1963, 67, 95-104.

Katz, I., Cohen, S., \& Glass, D. C. Some determinants of crossracial helping behavior. Journal of Personality and Social Psychology, 1975, 32, 964-970.

Kelley, H. H. Attribution in social interaction. In E. E. Jones et al. (Eds.), Attribution: Perceiving the causes of behavior. Morristown, N.J: General Learning Press, 1971.

Scheier, M. F., Carver, C. S., Schulz, R., Wishnick, G. I., Glass, D. C., \& KATz, I. Sympathy, self-consciousness, and reactions to the stigmatized. Journal of Applied Social Psychology, in press.

WINER, B. J. Statistical principles in experimental design. New York: McGraw-Hill, 1971.

Zillman, D., Johnson, R. C., \& DaY, K. D. Attribution of apparent arousal and proficiency of recovery from sympathetic activation affecting excitation transfer to aggressive behavior. Journal of Experimental Social Psychology, 1974, 10, 503-515.

(Received for publication October 9, 1978.) 